'Cooperativa Agroindustrial (C. Vale), Palotina, PR, Brasil

${ }^{2}$ Centro Universitărio Integrado, Rodovia BR 158, km 207, CEP 87300970 Campo Mourão, PR, Brasil ${ }^{3}$ Centro Estadual de Educação

Profissional Agricola, Campo Mourão, PR, Brasil

Instituto Federal de Santa Catarina, Campus Rio do Sul, Rio do Sul, SC, Brasil

${ }^{5}$ Sakata Seeds Sudamerica, Bragança Paulista, SP, Brasil

*autor correspondente

凶 leandro.meert@grupointegrado.br

\title{
Produtividade de milho segunda safra em função de diferentes velocidades de semeadura e densidade de plantas
}

\author{
Second season maize yield based on sowing speed and plant \\ population density
}

Clayton Vilmar Kopper ${ }^{1}$, Leandro Meert ${ }^{2 *}$, Antônio Krenski², Wagner Antonio Borghi Antonio Mendes de Oliveira Neto ${ }^{4}$, Alex Sandro Torre Figueiredo ${ }^{5}$

RESUMO: A implantação da cultura do milho deve ser cuidadosamente planejada, pois diferentemente de outras culturas, ela não compensa a ausência de plantas. Assim, o objetivo com este estudo foi avaliar os componentes de rendimento e a produtividade da cultura do milho implantada sob diferentes velocidades de semeadura e população de plantas. O trabalho foi conduzido no município de Mamborê - PR, no ano de 2015. O experimento foi em blocos casualizados em esquema fatorial (4 $\mathrm{x} 2)$, sendo quatro velocidades de semeadura $(5,7$, $\left.9 \mathrm{e} 11 \mathrm{~km} \mathrm{~h}^{-1}\right)$ e duas populações de plantas $(60.000$ e 70.000 plantas ha $\left.{ }^{-1}\right)$. O híbrido Balu 280PRO ${ }^{\circledR}$ foi semeado com espaçamento de $70 \mathrm{~cm}$ entre linhas. As variáveis respostas avaliadas foram a população final de plantas, altura de plantas, altura da inserção da primeira espiga, diâmetro de colmo, número de grãos por espiga, número de fileiras por espiga, massa de mil grãos e a produtividade. Com os resultados, foi observado que a população de plantas influenciou todas as variáveis respostas com a população de 70.000 plantas ha-1 $^{-1}$, proporcionando maior produtividade. $\mathrm{O}$ aumento da velocidade de semeadura reduziu a altura de plantas e a produtividade de grãos, mas esses efeitos foram menos intensos na população de 70.000 plantas ha $^{-1}$.

PALAVRAS-CHAVE: Arranjo de plantas, competição intraespecífica, semeadura.
ABSTRACT: Maize crop seeding requires a careful planning, because, different from others crops, there is no compensation for plants absence. Thus, this work aimed to evaluate both corn yield and productivity components under different sowing speeds and plant population. The experiment was performed in the municipality of Mamborê-PR, using a randomized blocks design and factorial arrange (4 $\times 2$ 2), with four sowing speeds (5, 7, 9 and $11 \mathrm{~km} \mathrm{h-1)}$ and two-plant population densities (60,000 and 70,000 plants ha-1). The Balu $280 \mathrm{PRO}^{\circledR}$ hybrid was sowed with 0.70 m of spacing between rows. The following variables were evaluated: final plant population, plant height, first ear height insertion, stalk diameter, grain number per ear, kernel row number per ear, thousand grain mass and yield. Results showed that plant population density influenced all variable analyzed for 70,000 plants $h a^{-1}$ population, resulting in the highest yield. The increase in sowing speed reduced corn height and yield, but these effects were less intense in the population of 70,000 plants $\mathrm{ha}^{-1}$.

KEYWORDS: Plants design, intraspecific competition, sowing.

\section{Introdução}

A segunda safra de milho possui grande importância para o agronegócio brasileiro, pois representa $66 \%$ da produção total do grão no país e também possibilita a otimização da mão de obra e maquinários da propriedade, diminuindo assim a sazonalidade da produção. No ano agrícola 2015/2016, a produção total de milho foi de 83,3 milhões de toneladas em 15,6 milhões de hectares (COMPANHIA..., 2016). 
A semeadura do milho, independentemente da época, deve ser planejada corretamente, pois a cultura, diferentemente de outras (soja, arroz, trigo), não compensa a falta de plantas em caso de falhas na semeadura. Assim, é primordial que se atinja a população ideal, pois as plantas que faltarem impactarão negativamente em componentes de produção, principalmente no número de espigas por unidade de área.

A velocidade de deslocamento da semeadora tem influência direta sobre a distribuição das sementes no sulco de semeadura. Assim, quando se aumenta a velocidade de deslocamento da semeadora, ocorre maior patinagem dos rodados da máquina, aumentando a ocorrência de plantas duplas, alterando a qualidade de semeadura (GARCIA et al., 2011). Vieira e Reis (2001) observaram que a velocidade de deslocamento ideal para a semeadura é aquela em que o sulco é aberto e fechado sem remover exageradamente o solo, permitindo a distribuição das sementes com espaçamentos e profundidades constantes.

Ao avaliarem as velocidades de deslocamento de $6,8 \mathrm{e} 9 \mathrm{~km} \mathrm{~h}^{-1}$, Canova et al. (2007) constataram que o aumento na velocidade interferiu na distribuição de sementes, onde a menor velocidade proporcionou densidades de semeadura mais próximas da ideal. Silva et al. (2000), conduzindo seu estudo com diferentes velocidades de deslocamento no cultivo de milho com semeadora equipada com dosador de sementes do tipo disco horizontal, concluíram que o número de plantas por metro linear foi menor quando se aumentou a velocidade, sendo que a melhor distribuição espacial de plantas se deu em $3 \mathrm{~km} . \mathrm{h}^{-1}$.

Portanto, o adequado arranjo espacial de plantas é determinante para o rendimento de grãos de milho, pois o arranjo afeta a arquitetura, o crescimento, a partição de fotoassimilados e a produtividade de grãos (ALMEIDA et al., 2000). Fancelli e Dourado Neto (2004) comentam que um dos motivos para o baixo rendimento do milho é a utilização de populações inadequadas. Argenta et al. (2001) citam que é necessário reavaliar as recomendações de densidade para a cultura do milho devido às modificações ocorridas nos híbridos com relação à altura de plantas, arquitetura foliar, altura de inserção de espiga e potencial produtivo.

Desse modo, ambientes de produção distintos podem proporcionar aumento na população de plantas alterando a produtividade de grãos (MARCHÃO et al., 2005).

Nesse contexto, o estudo avaliou a influência de diferentes velocidades de semeadura e população de plantas sobre as características agronômicas e produtividade da cultura do milho segunda safra.

\section{Material e Métodos}

O trabalho foi realizado na Fazenda Caravajo, localizada no

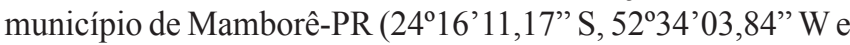
altitude de 690 metros). O solo da área é classificado como Latossolo Vermelho Distroférrico (EMPRESA..., 2013). As características químicas do solo na camada de $0-20 \mathrm{~cm}$ são: $\mathrm{pH} \mathrm{CaCl}_{2} 5,3 ; \mathrm{H}+\mathrm{Al}$ (SMP) 5,04 $\mathrm{cmol} \mathrm{dm}^{-3}$; matéria orgânica 2,67\%; P (Mehlich 1)

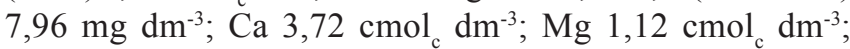
$\mathrm{K} 0,23 \mathrm{cmol}_{\mathrm{c}} \mathrm{dm}^{-3} \mathrm{e} \mathrm{V} 50,15 \%$. O experimento foi conduzido em blocos casualizados, disposto em arranjo fatorial $4 \times 2$, sendo quatro velocidades de semeadura $\left(5,7,9\right.$ e $\left.11 \mathrm{~km} \mathrm{~h}^{-1}\right) \mathrm{e}$ duas populações de plantas $\left(60.000\right.$ e 70.000 plantas ha $\left.^{-1}\right)$, com quatro repetições. Cada parcela foi formada por cinco linhas de 12 metros de comprimento.

A semeadura foi realizada no dia 05 de março de 2015, utilizando uma semeadora-adubadora Tatu Marchesan PST3 de arrasto, com seis linhas de semeadura, espaçadas entre si $0,70 \mathrm{~m}$ com disco de semente horizontal com 28 furos. O trator utilizado foi um CASE IH Maxxum 150 TDA, potência de $149 \mathrm{cv}$, a variação da velocidade foi realizada com o auxílio do velocímetro do trator. A variação das populações foi realizada mudando-se as relações de transmissão da semeadora. O híbrido utilizado foi o BALU $280 \mathrm{PRO}^{\circledR}$ superprecoce, e a adubação de base feita com $20 \mathrm{~kg} \mathrm{ha}^{-1}$ de nitrogênio, $50 \mathrm{~kg} \mathrm{ha}^{-1}$ de $\mathrm{P}_{2} \mathrm{O}_{5}$ e $50 \mathrm{~kg} \mathrm{ha}^{-1}$ de $\mathrm{K}_{2} \mathrm{O}$, a adubação de cobertura foi realizada com $52 \mathrm{~kg} \cdot \mathrm{ha}^{-1}$ de nitrogênio no estádio $\mathrm{V} 4$, sendo que as fontes de nitrogênio, fósforo e potássio foram, respectivamente, ureia, superfosfato simples e cloreto de potássio.

Durante o experimento foi realizada uma aplicação em pós emergência de atrazina (1.653 g i.a. ha ${ }^{-1}$ ) para o controle de plantas daninhas, três aplicações de imidacloprido $\left(100\right.$ g i.a ha $\left.^{-1}\right)+$ bifentrina $\left(20\right.$ g i.a. ha $\left.{ }^{-1}\right)$, visando o controle do percevejo-barriga-verde, e para o controle de doenças foram realizadas duas aplicações de piraclostrobina $\left(80,57 \mathrm{~g}\right.$ i.a. ha $\left.{ }^{-1}\right)$ + epoxiconazol (49,58 g i.a. ha $\left.{ }^{-1}\right)$.

As variáveis respostas avaliadas no experimento foram: Estande final: Com o auxílio de uma trena mediram-se seis metros das duas linhas centrais, contando-se o número de plantas e extrapolando-se o valor para plantas por ha ${ }^{-1}$; Altura de planta e altura de inserção da espiga: Ambas foram realizadas em 10 plantas das duas linhas centrais com o auxílio de uma trena; Diâmetro do colmo: Com o auxílio de um paquímetro digital mediu-se o colmo de 10 plantas a $10 \mathrm{~cm}$ do solo; Número de grãos por espiga e número de fileiras por espiga: Realizados após a colheita, separando-se 10 espigas de modo aleatório, e feitas as respectivas contagens; Massa de mil grãos: Foi feita segundo a metodologia descrita na Regra para análise de sementes (BRASIL, 2009), onde se utilizaram 8 repetições com 100 sementes, extrapolando-se a massa em gramas para 1000 grãos; Produtividade: colheram-se $2,5 \mathrm{~m}^{2}$ da área central de cada parcela, debulharam-se manualmente e a umidade foi corrigida para $13 \%$, e em seguida extrapolou-se a quantidade obtida na parcela para hectare.

Os resultados obtidos foram submetidos à análise de variância pelo teste $\mathrm{F}$, e em seguida procedeu-se à análise de regressão para o fator velocidade, onde se adotou o modelo de maior significância e teste de Tukey para os dois níveis de população de plantas a $p<0,05$ de probabilidade de erro com o auxílio do programa estatístico Sisvar. A correlação de Pearson foi realizada no Microsoft Excel versão 2010 com o auxílio da extensão Action 2.9.

\section{Resultados e Discussão}

Pode-se verificar, de acordo com a Tabela 1, que a velocidade de deslocamento influenciou somente a altura de inserção de espigas e a produtividade. A população de plantas não 
influenciou a altura de plantas, altura de inserção de espigas e o diâmetro do colmo e a interação entre os fatores velocidade $(\mathrm{V})$ e população de plantas (P). A interação (V x P) foi significativa somente para a altura de plantas, número de grãos por espiga e produtividade. Assim, opta-se apenas pela apresentação dos resultados significativos $(\mathrm{p}<0,05)$.

Na Figura 1 podem ser observados os dados de precipitação pluvial e temperatura do ar durante os meses de realização do trabalho. A temperatura média mínima foi de $15^{\circ} \mathrm{C}$ e a média máxima de $26^{\circ} \mathrm{C}$. Fancelli e Dourado Neto (2004) citam que a máxima eficiência de conversão da radiação solar é afetada pelas temperaturas diurnas e noturnas, e também pela amplitude térmica resultante. Desse modo, temperaturas diurnas elevadas e noturnas amenas possibilitam maior saldo de fotoassimilados e aumento da produtividade.

O regime hídrico ficou dentro do ideal para a cultura que segundo Fancelli e Dourado Neto (2004) deve ser de 350-500 mm de precipitação, portanto, não sendo um fator limitante. Esses dois fatores acima citados ajudam a explicar a alta produtividade obtida no trabalho que está de acordo com a produtividade de milho segunda safra no município de Mamborê que de acordo com a Seab (SECRETARIA..., 2016) é de aproximadamente $6000 \mathrm{~kg} \mathrm{ha}^{-1}$.

Com relação ao número de grãos por espiga e o número de fileiras por espiga, esses foram superiores com população de 60 mil plantas por ha ${ }^{-1}$, conforme pode ser observado na Tabela 2, demonstrando que a intensificação da competição intraespecífica prejudicou a formação da espiga. Scheeren et al. (2004) observaram redução em ambos componentes quando a população de plantas foi aumentada.

Isso ocorre porque o aumento na densidade de plantas leva à intensificação da competição pelos recursos do meio como água, luz e nutrientes, o que limita a produção individual da planta (PIANA et al., 2008). Marchão et al. (2005) observaram em seus estudos sobre densidade de plantas e características agronômicas de híbridos de milho sob espaçamento reduzido entre linhas que a alta densidade de plantas pode levar ao aumento da esterilidade feminina, reduzindo assim o número de grãos por espiga.

Por outro lado, verificou-se que a massa de mil grãos e a produtividade foram significativamente superiores na população de 70 mil plantas ha ${ }^{-1}$. Possivelmente, a menor quantidade de grãos na espiga contribuiu para este fato, já que se espera uma relação inversa entre a quantidade e a massa dos grãos por espiga. Silva et al. (2008) conseguiram incremento de $2.464 \mathrm{~kg} \mathrm{ha}^{-1}$ na produtividade com o aumento da população de 40 para 80 mil plantas ha-1. Scheeren et al. (2004) aumentaram a produtividade em $1704 \mathrm{~kg} \mathrm{ha}^{-1}$ quando

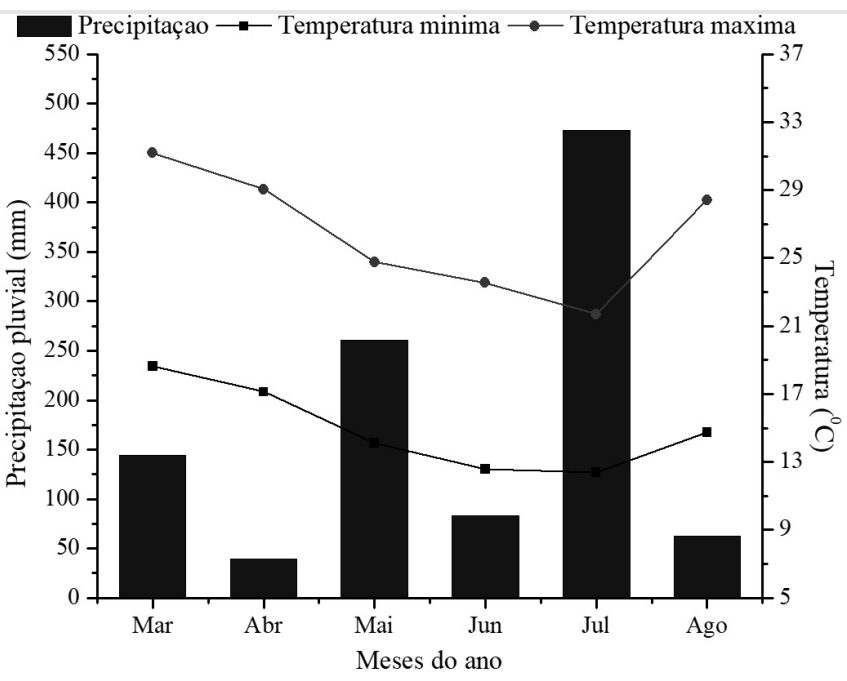

Figura 1. Dados de precipitação pluvial (mm) e temperatura mínima e máxima $\left({ }^{\circ} \mathrm{C}\right)$ registrado no município de Mamborê-PR entre os meses de março e agosto de 2015. Mamborê-PR, 2015.

Tabela 1. Resumo das análises de variância (F calculado e CV (\%)) para altura de planta (AP), altura de inserção de espigas (AIE), diâmetro do colmo (DC), número de fileiras por espiga (NFE), número de grãos por espiga (NGE), massa de mil grãos (MMG), produtividade (PROD) e população final (PF). Mamborê-PR, 2015.

\begin{tabular}{|c|c|c|c|c|c|c|c|c|}
\hline FATORES & $\mathbf{A P}$ & AIE & DC & NFE & NGE & MMG & PROD & $\mathbf{P F}$ \\
\hline Velocidade (V) & $16,97^{\mathrm{ns}}$ & $17,47 *$ & $0,28^{\mathrm{ns}}$ & $3,27^{\mathrm{ns}}$ & $3,78^{\text {ns }}$ & $1,37^{\mathrm{ns}}$ & $19,73 *$ & $723,20^{\text {ns }}$ \\
\hline População (P) & $2,2 \mathrm{~ns}$ & $2,0 \mathrm{~ns}$ & $5,0 \mathrm{~ns}$ & $6,48 *$ & $13,73 *$ & $11,03 *$ & $4,50 *$ & $212,63 *$ \\
\hline$V \times P$ & $3,69 *$ & $13,20^{\mathrm{ns}}$ & $0,17^{\text {ns }}$ & $1,07^{\mathrm{ns}}$ & $1,58 *$ & $0,90^{\mathrm{ns}}$ & $3,46 *$ & $24,15^{\text {ns }}$ \\
\hline CV (\%) & 2,1 & 3,4 & 3,8 & 3,42 & 4,26 & 5,13 & 7,74 & 4,00 \\
\hline
\end{tabular}

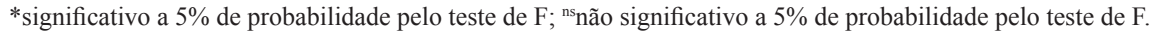

Tabela 2. Número de grãos por espiga (NGE), número de fileiras por espiga (NFE), massa de mil grãos (MMG em g) e produtividade (PROD em kg ha-1) de milho segunda safra produzido em duas populações diferentes. Mamborê-PR, 2015.

\begin{tabular}{|c|c|c|c|c|}
\hline População (plantas ha-1) & NGE & NFE & MMG & PROD \\
\hline 60000 & $493,20 a^{*}$ & $15,67 a$ & $364,38 b$ & $7552,57 b$ \\
\hline 70000 & $466,43 b$ & $15,20 \mathrm{~b}$ & $387,03 a$ & $8004,52 a$ \\
\hline DMS & 14,90 & $\mathbf{0 , 3 8}$ & 14,07 & 439,51 \\
\hline CV\% & 4,26 & 3,42 & 5,13 & 7,74 \\
\hline
\end{tabular}

*Médias seguidas pela mesma letra na coluna não diferem entre si pelo teste de Tukey $\alpha<0,05$. 
acrescentaram 37.500 plantas a mais por hectare. Kappes et al. (2011) verificaram decréscimo linear na massa de mil grãos em função do aumento da população, onde houve redução de aproximadamente $46 \mathrm{~g}$ para cada 10 mil plantas acrescidas na população.

Quando se observa o incremento de produtividade em função do aumento na população de plantas, esse pode ser devido ao ajuste no desenvolvimento da planta em função da população (BORGHI; MELLO; CRUSCIOL, 2004) e também ao maior número de plantas por área (PENARIOL et al., 2003).

A altura de plantas apresentou comportamento quadrático em função da velocidade de deslocamento do conjunto trator + semeadora. Para a população de 70 mil plantas, a maior altura foi obtida com a velocidade de $6,66 \mathrm{~km} \mathrm{~h}^{-1}$, e para a de 60 mil, $6,89 \mathrm{~km} \mathrm{~h}^{-1}$ (Figura 2) para as duas populações testadas. Este resultado pode ser atribuído à diminuição no número de plantas por área que diminui a competição por luz, e com isso as plantas tendem a crescer menos.

Segundo Bottega et al. (2014), a redução na altura das plantas nas maiores velocidades pode estar associada à maior ocorrência de falhas nas linhas de semeadura, já que, com o aumento na velocidade de deslocamento do conjunto trator-semeadora, as sementes não são colocadas corretamente no sulco, dificultando a germinação. Assim, o menor número de plantas na linha reduz a competição por luz, acarretando em menor altura da planta. Apesar de não haver ajuste de equação para os modelos testados, houve redução da população de plantas com o acréscimo da velocidade de deslocamento.

Resultados semelhantes foram encontrados por Silva et al. (2000) estudando o desempenho de uma semeadora-adubadora no estabelecimento e na produtividade da cultura do milho sob plantio direto, onde velocidades acima de $6 \mathrm{~km} \mathrm{~h}^{-1}$ promoveram a redução no tamanho das plantas e altura de inserção de espigas. Os autores também verificaram que o aumento da velocidade proporcionou redução no número de plantas por metro linear.

A altura de inserção de espigas também apresentou comportamento quadrático, com o ponto de máxima na velocidade de 6,53 $\mathrm{km} \mathrm{h}^{-1}$ (Figura 3).

Para o número de grãos por espiga, de acordo com a Figura 4, o comportamento foi distinto para as duas populações, onde na maior população a velocidade não afetou essa variável. Já na população de 60 mil plantas ha ${ }^{-1}$ houve decréscimo no número de grãos por espiga com o aumento da velocidade do conjunto trator-semeadora. Uma provável explicação para esses resultados é a menor polinização das plantas, devido ao menor número de plantas por área. No entanto, Mello et al. (2007), em seus estudos sobre a produtividade de híbridos de milho em função da velocidade de semeadura, não observaram alterações no número de grãos por fileira.

Observando a produtividade, Figura 5, ela foi afetada pelo aumento da velocidade de deslocamento do conjunto, independentemente da população de plantas. Esses resultados são devido à menor quantidade de plantas por área, o que reduz o número de espigas e consequentemente a produtividade. Silva et al. (2000) observaram redução de $12 \%$ na produtividade quando aumentaram a velocidade de 3 para $11,2 \mathrm{~km} \mathrm{~h}^{-1}$ Garcia et al. (2006) verificaram redução linear da produtividade com o aumento da velocidade de semeadura. Os autores

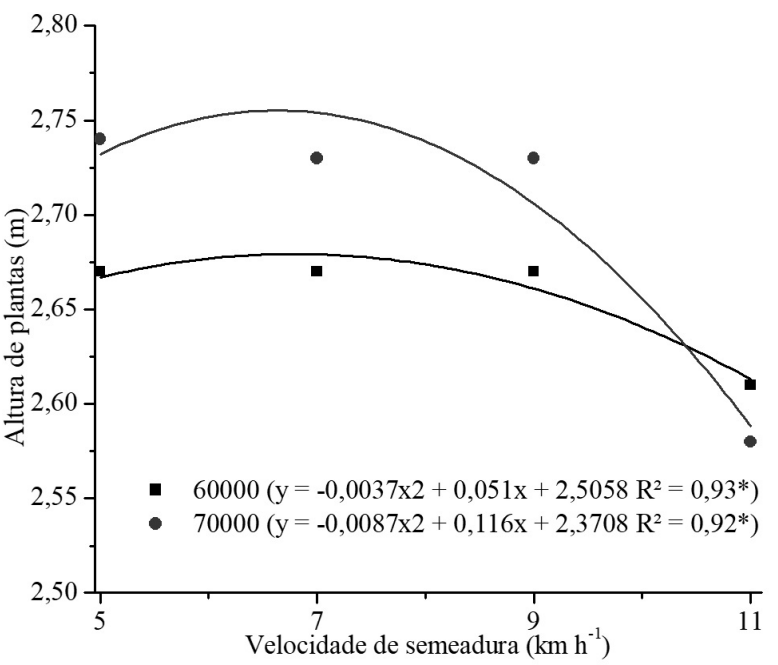

Figura 2. Altura de plantas de milho segunda safra (m) em função de quatro velocidades de semeadura, para duas densidades de semeadura. Mamborê-PR, 2015. *Significativo a $\alpha<0,05$ de probabilidade.

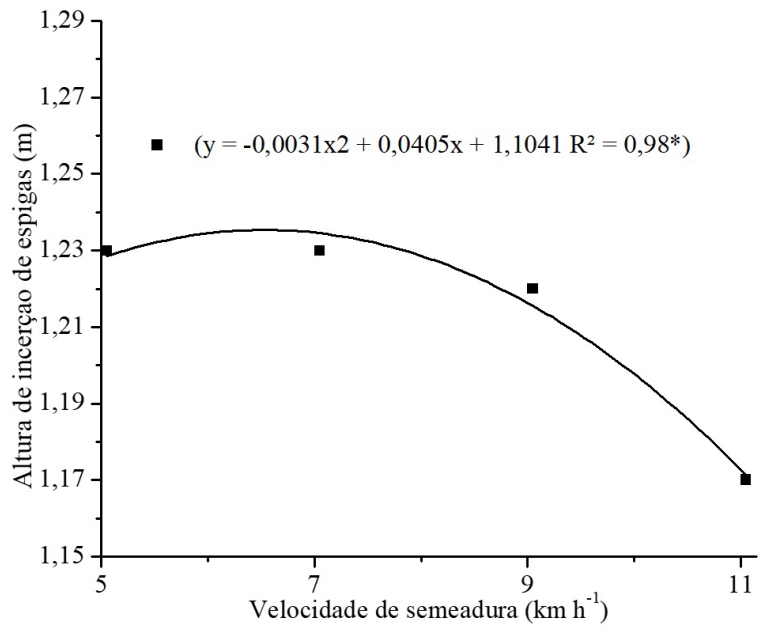

Figura 3. Altura de inserção de espigas de milho segunda (m) safra em função de quatro velocidades de semeadura, Mamborê-PR, 2015. *Significativo a $\alpha<0,05$ de probabilidade.

ainda citam que a produtividade somente será afetada pela velocidade, caso esta reduza o número de plantas por área (MELLO et al., 2007).

Assim, observando o meio agrícola nos últimos anos, percebe-se um aumento no tamanho das máquinas e incremento na velocidade das operações, porém isso é realizado sem considerar os aspectos técnicos e o impacto sobre o rendimento da cultura, onde o principal entrave para a semeadura de qualidade no cultivo do milho está na velocidade de deslocamento do conjunto trator-semeadora. Pesquisas têm demostrado que não se deve trabalhar com velocidades muito elevadas que não permitam a correta deposição da semente no sulco e posterior cobrimento (JANDREY, 2015).

Quanto à correlação de Pearson entre as variáveis (Tabela 3), a altura de planta e altura de inserção de espigas apresentaram 
Tabela 3. Matriz de correlação linear de Pearson para diâmetro do colmo (DC), altura de planta (AP), altura de inserção de espiga (AIE), número de fileiras por espiga (NFE), número de grãos por espiga (NGE), massa de mil grãos (MMG) e produtividade (PROD), Mamborê-PR, 2015.

\begin{tabular}{|c|c|c|c|c|c|c|c|}
\hline & DC & AP & AIE & NFE & NGE & MMG & PROD \\
\hline DC & 1 & & & & & & \\
\hline $\mathbf{A P}$ & $-0,08$ & 1 & & & & & \\
\hline AIE & $-0,11$ & $0,62 *$ & 1 & & & & \\
\hline NFE & 0,02 & $-0,23$ & $-0,05$ & 1 & & & \\
\hline NGE & 0,16 & $-0,24$ & 0,01 & $0,86^{*}$ & 1 & & \\
\hline MMG & $-0,15$ & 0,28 & 0,14 & $-0,60 *$ & $-0,66 *$ & 1 & \\
\hline PROD & 0,04 & 0,30 & $0,42 *$ & 0,18 & $\mathbf{0 , 3 0}$ & $\mathbf{0 , 2 0}$ & 1 \\
\hline
\end{tabular}

Significativo pelo teste de $\mathrm{t} ; *$ valor-p $<0,05$.

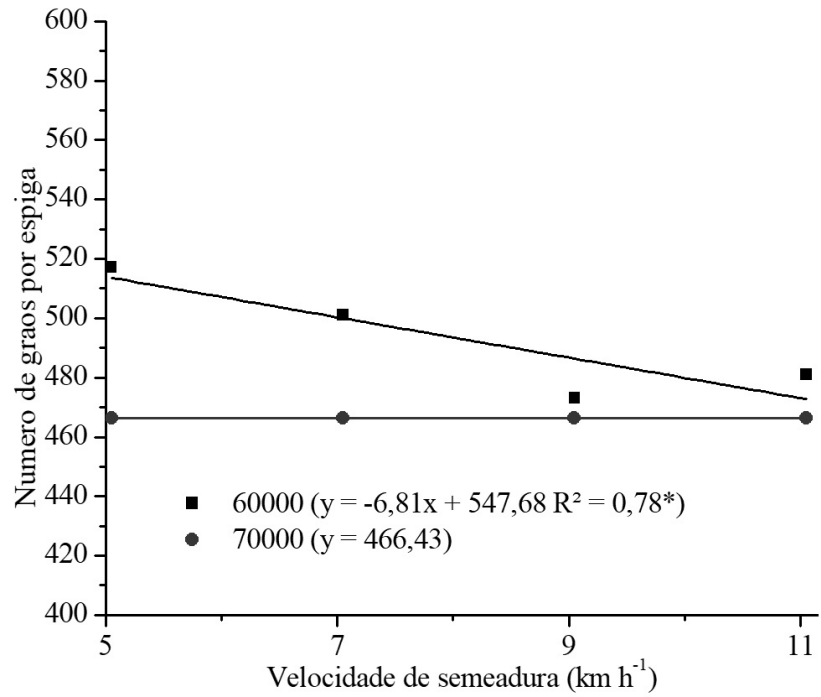

Figura 4. Número de grãos por espiga de milho segunda safra em função de quatro velocidades de semeadura e duas populações de plantas, Mamborê-PR 2015. *Significativo a $\alpha<0,05$ de probabilidade.

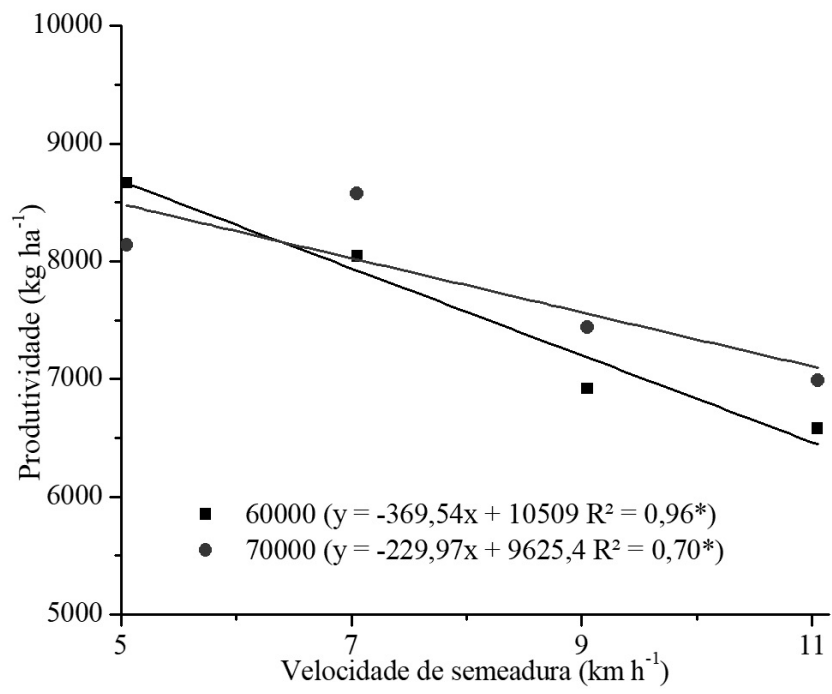

Figura 5. Produtividade de milho segunda safra $\left(\mathrm{kg} \mathrm{ha}^{-1}\right)$ em função de quatro velocidades de semeadura e duas populações de plantas. Mamborê-PR, 2015. *Significativo a $\alpha<0,05$ de probabilidade. correlação positiva $(0,62)$; o número de fileiras por espiga e o número de grãos por espigas também apresentaram correlação positiva $(0,86)$, colaborando com resultados encontrados por Lopes et al. (2007) que obtiveram correlação de 0,60 . Verificou-se também que o número de fileiras por espiga afeta negativamente a massa de mil grãos $(-0,60)$, pois quando um aumenta o outro diminui.

Já a massa de mil grãos e o número de grãos por espiga apresentam correlação negativa $(-0,66)$, pois à medida que diminui o número de grãos na espiga ocorre maior alocação de fotoassimilados para os grãos restantes, proporcionando maior massa. Lopes et al. (2007), observando as relações de causa e efeito em espigas de milho relacionadas aos tipos de híbridos, verificaram resultados semelhantes aos encontrados nesse estudo.

A variável produtividade foi afetada diretamente apenas pela altura de inserção de espigas $(0,42)$, mostrando que plantas com espigas inseridas em maior altura tendem a produzir mais. Bello et al. (2010) e Souza et al. (2014) observaram que a inserção das espigas foi a variável que apresentou maior correlação com a produtividade, e considerada um parâmetro agronômico importante em híbridos de alto rendimento.

\section{Conclusão}

O fator população de plantas influencia todas as variáveis respostas analisadas, onde a população de 70 mil plantas ha ${ }^{-1}$ foi a que proporciona a maior produtividade.

$\mathrm{O}$ incremento na velocidade de semeadura reduz a altura de plantas e a produtividade de grãos.

A população de 70 mil plantas ha-1 apresenta menor queda de produtividade com o aumento da velocidade de semeadura.

A altura de inserção de espigas é uma variável que possui alta influência sobre a produtividade.

\section{Referências}

ALMEIDA, M. L. et al. Incremento na densidade de plantas: uma alternativa para aumentar o rendimento de grãos de milho em regiões de curta estação estival de crescimento. Ciência Rural, Santa Maria, v. 30, n. 1, p. 23-29, 2000. 
ARGENTA, G. et al. Resposta de híbridos simples de milho à redução do espaçamento entre linhas. Pesquisa Agropecuária Brasileira, Brasília, v. 36, n. 1, p. 71-78, 2001.

BELLO, O. B. et al. Correlation and path coefficient analysis of yield and agronomic characters among open pollinated maize varieties and their hybrids in a diallel cross. African Journal of Biotechnology, Pretória, v. 9, n. 18, p. 2633-2639, 2010.

BORGHI, E.; MELLO, L. M. M.; CRUSCIOL, C. A. C. Adubação por área e por planta, densidade populacional e desenvolvimento do milho em função do sistema de manejo do solo. Acta Scientiarum, Maringá, v. 26, n. 3, p. 337-345, 2004.

BOTTEGA, E. L. et al. Efeitos da profundidade e velocidade de semeadura na implantação da cultura do milho. Pesquisa Agropecuária Pernambucana, Recife, v. 19, n. 2, p. 74-78, 2014.

BRASIL. Ministério da Agricultura, Pecuária e Abastecimento. Regras para análise de sementes. Brasília: Mapa/ACS, 2009. 395 p.

CANOVA, R. et al. Distribuição de sementes por uma semeadoraadubadora em função de alterações mecanismo dosador e de diferentes velocidades de deslocamento. Engenharia na Agricultura, Jaboticabal, v. 15, n. 3, p. 299-306, 2007.

COMPANHIA NACIONAL DE ABASTECIMENTO - CONAB. Acompanhamento da safra brasileira de grãos. Brasília: $C O N A B$, 2016. v. 3, n. 5, 178 p.

EMPRESA BRASILEIRA DE PESQUISA AGROPECUÁRIA EMBRAPA. Centro Nacional de Pesquisa de Solo. Sistema Brasileiro de Classificação de Solos. $3^{\mathrm{a}}$ ed. Rio de Janeiro: CNPS, 2013. 353 p.

FANCELLI, A. L.; DOURADO NETO, D. Produção de milho. 2. ed. Guaíba: Agropecuária, 2004. 360 p.

GARCIA, L. C. et al. Influência da velocidade de deslocamento na semeadura do milho. Engenharia Agrícola, Jaboticabal, v. 26, n. 2, p. 520-527, 2006.

GARCIA, R. F. et al. Influência da velocidade de deslocamento no desempenho de uma semeadora-adubadora de precisão no Norte Fluminense. Acta Scientiarum Agronomy, Maringá, v. 33, n. 3, p. 417-422, 2011.

JANDREY, D. Manejo de milho para altos rendimentos. 2015. Disponível em: $<$ http://www.pioneersementes.com.br/media-center/ artigos/180/manejo-de-milho-para-altos-rendimentos $>$. Acesso em: 07 de maio de 2016.

KAPPES, C. et al. Desempenho de híbridos de milho em diferentes arranjos espaciais de plantas. Bragantia, Campinas, v. 70, n. 2, p. 334-343, 2011.
LOPES, S. J. et al. Relações de causa e efeito em espigas de milho relacionadas aos tipos de híbridos. Ciência Rural, Santa Maria, v. 37, n. 6, p. 1536-1542, 2007.

MARCHÃO, R. L. et al. Densidade de plantas e características agronômicas de híbridos de milho sob espaçamento reduzido entre linhas. Pesquisa Agropecuária Tropical, Goiânia, v. 35, n. 2, p. 93-101, 2005.

MELLO, A. J. R. et al. Produtividade de híbridos de milho em função da velocidade de semeadura. Engenharia Agrícola, Jaboticabal, v. 27 , n. 2, p. 479-486, 2007.

PENARIOL, F. G. et al. Comportamento de cultivares de milho semeadas em diferentes espaçamentos entre linhas e densidades populacionais, na safrinha. Revista Brasileira de Milho e Sorgo. Sete Lagoas, v. 2, n. 2, p. 52-60, 2003.

PIANA, A. T. et al. Densidade de plantas de milho híbrido em semeadura precoce no Rio Grande do Sul. Ciência Rural, Santa Maria, v. 38, n. 9, p. 2608-2612, 2008.

SCHEEREN, B. R. et al. Arranjo populacional para a cultura do milho na região central do Estado de Mato Grosso do Sul. Acta Scientiarum Agronomy, Maringá, v. 26, n. 2, p. 55-60, 2004.

SECRETARIA DA AGRICULTURA E DO ABASTECIMENTO SEAB. Produção agropecuária. 2016. Disponível em: $<\mathrm{http}: / / w w w$. agricultura.pr.gov.br/modules/conteudo/conteudo.php?conteudo=137>. Acesso em: 7 maio 2016.

SILVA, A. G. et al. Influência da população de plantas e do espaçamento entre linhas nos caracteres agronômicos do híbrido de milho P30K75 em Rio Verde, Goiás. Bioscience Journal, Uberlândia, v. 24, n. 2, p. p. 89-96, 2008.

SILVA, J. G.; KLUTHCOUSKI, J.; SILVEIRA, P. M. Desempenho de uma semeadora-adubadora no estabelecimento e na produtividade da cultura do milho sob plantio direto. Scientia Agrícola, Piracicaba, v. 57, n. 1, p. 7-12, 2000.

SOUZA, T. V. et al. Relações entre componentes de rendimento e características morfológicas de milho. Magistra, Cruz das Almas, v. 26, n. 4, p. 495-506, 2014.

VIEIRA, L. B.; REIS, E. F. Máquinas para o plantio direto. Belo Horizonte: EPAMIG, 2001. p. 43-48.

Recebido: 09 set. 2016 Aprovado: 02 jan. 2018 